\section{Becquerel, Henri}

T. Arndt

Bioscientia Institut für Medizinische Diagnostik $\mathrm{GmbH}$, Ingelheim, Deutschland

Lebensdaten Geb. 15. Dezember 1852 in Paris, gest. 25. August 1908 in Le Croisic.

Verdienste Professor der Physik in Paris. Entdecker der Radioaktivität, die er 1896 an Uransalzen beobachtete. Das nach ihm benannte Maß der Radioaktivität eines Stoffes ist das Becquerel $(\mathrm{Bq})$, entsprechend 1 radioaktiven Zerfall pro Sekunde. Auf seiner Entdeckung basierend isolierte das Ehepaar Curie aus Pechblende Radium. Nobelpreis für Physik 1903 gemeinsam mit Marie und Pierre Curie.

\section{Literatur}

Falbe J, Regitz M (Hrsg.) Römpp Chemie Lexikon. 9. Aufl., Georg Thieme, Stuttgart New York, 1989. 